\title{
Modifikasi Perencanaan Struktur Apartemen One East Residence Surabaya dengan Menggunakan Struktur Komposit Baja Beton dan Base Isolator: High Damping Rubber Bearing (HDRB)
}

\author{
Adnan Fadhlullah Muharam, Endah Wahyuni dan Data Iranata \\ Departemen Teknik Sipil, Fakultas Teknik Sipil dan Perencanaan, Institut Teknologi Sepuluh Nopember (ITS) \\ e-mail:endah@ce.its.ac.id
}

\begin{abstract}
Abstrak - Pada saat ini, penggunaan struktur komposit bajabeton dalam pembangunan konstruksi sipil sangatlah banyak dilakukan. Komponen struktur komposit ini dapat menahan beban sekitar $33 \%$ sampai $50 \%$ lebih besar daripada beban yang dapat dipikul oleh balok baja saja tanpa adanya perilaku komposit. Penggunaan teknologi Base Isolator sebagai peredam gempa juga dinilai sangat penting bagi konstruksi bangunan gedung karena mengurangi gaya gempa yang diterima oleh struktur. Apartemen One East Residence Surabaya pada kondisi sebenarnya dibangun dengan menggunakan struktur beton bertulang biasa dan memiliki 33 lantai dan 1 basement. Dalam Studi ini, gedung tersebut akan dimodifikasi dengan menggunakan struktur komposit bajabeton dan Base Isolator: High Damping Rubber Bearing (HDRB). Berdasarkan perhitungan dan analisa struktur didapatkan hasil, yaitu: tebal pelat atap $9 \mathrm{~cm}$, pelat lantai 9 cm, dimensi balok anak terbesar WF 450x300x11x18, dimensi balok induk terbesar WF $800 \times 300 \times 14 \times 26$, dimensi kolom terbesar HSS 700x700x $28 \times 28$ berintikan beton, dimensi base isolator eksterior $900 \mathrm{~mm}$, dimensi base isolator interior 1100 $\mathrm{mm}$, pondasi menggunakan bored pile diameter $80 \mathrm{~cm}$ dengan kedalaman $30 \mathrm{~m}$, dimensi pedestal terbesar $1500 \mathrm{~mm}$, dimensi pilecap terbesar 960x640x110 $\mathrm{cm}$ dan dimensi sloof $450 \times 600$ mm. Perencanaan tersebut telah memenuhi persyaratan keamanan struktur berdasarkan SNI 1727:2013, SNI 1726:2012, SNI 1729:2015 dan SNI 2847:2013.
\end{abstract}

Kata Kunci-Apartemen, Base Isolator, High Damping Rubber Bearing, Struktur Komposit Baja-Beton.

\section{PENDAHULUAN}

\section{A. Latar Belakang}

Surabaya dan kota-kota di sekitarnya dilewati patahan Kendeng dan Rembang. Selain itu dalam sejarahnya, tahun 1937 pernah ada gempa besar (6 -7 SR) di Mojokerto yang tak jauh dari Surabaya, Sesar Kendeng masih aktif dengan pergerakan $5 \mathrm{~mm}$ per tahun. Sesar Kendeng adalah "sambungan" dari Sesar Wetar dan Flores yang "merentang" hingga utara Bali, masuk ke daratan Jawa. Berdasarkan kajian sementara, struktur tanah Surabaya rentan. Karena dia terbentuk dari tanah endapan sungai dan endapan laut (alivium). Gedung-gedung bertingkat atau pencakar langit rawan terhadap guncangan gempa karena terjadinya resonansi dengan gelombang gempa [1].

Sebagai bagunan tinggi (Highrise building) Apartemen One East Residance perlu di desain tahan terhadap gempa. Kerusakan gempa secara konvensional dapat dicegah dengan memperkuat struktur bangunan terhadap gaya gempa yang bekerja. Seiring dengan perkembangan teknologi, salah satu metode yang dapat meredam energi gempa adalah dengan base isolator. Base isolator mempunyai sifat yang fleksibel terhadap gaya horisontal, tapi mampu menahan berat bangunan dengan baik. Hal itu dikarenakan kombinasi antara material karet dan pelat baja yang tersusun. Dengan sifat fleksibel tersebut, saat gaya gempa menggeser pondasi, base isolator melakukan simpangan horisontal bolak-balik dari tanah sehingga gaya tersebut hanya sebagian kecil yang diterima ke struktur bangunan [2].

Selain itu, untuk memberikan kekuatan yang lebih besar dalam memikul beban, maka diperlukan modifikasi perencanaan dengan menggunakan struktur komposit baja beton. Struktur komposit terbukti mampu memberikan kinerja yang lebih baik dibandingkan dengan struktur biasa dan menjadi lebih populer dalam rekayasa struktur [3].

\section{B. Rumusan Masalah}

Masalah utama pada penulisan Studi ini adalah bagaimana merencanakan gedung dengan struktur komposit baja-beton dan Base Isolator: High Damping Rubber Bearing (HDRB). Adapun perincian dari masalah di atas adalah sebagai berikut:

1. Bagaimana merencanakan struktur sekunder yang meliputi pelat, balok anak, tangga dan lift?

2. Bagaimana merencanakan struktur primer gedung menggunakan komposit baja-beton dengan peraturan yang berlaku?

3. Bagaimana merencanakan Base Isolator: High Damping Rubber Bearing (HDRB)?

4. Bagaimana merencanakan pondasi sesuai dengan beban yang dipikul struktur?

5. Bagimana menjelaskan hasil akhir perencanaan modifikasi dalam bentuk gambar teknik?

\section{Batasan Masalah}

Batasan masalah dalam penulisan Studi ini adalah sebagai berikut:

1. Base Isolator menggunakan tipe High Damping Rubber Bearing (HDRB).

2. Analisa struktur menggunakan program SAP 2000

3. Tidak membuat metode pelaksanaan di lapangan, arsitektural, manajemen konstruksi, dan perhitungan analisa biaya.

4. Perencanaan tidak meliputi instalasi mechanical electrical, dan sanitasi. 


\section{TINJAUAN PUSTAKA}

\section{A. Struktur Komposit Baja Beton}

Struktur komposit merupakan struktur yang terdiri dari dua material atau lebih dengan sifat bahan yang berbeda dan membentuk satu kesatuan sehingga menghasilkan sifat gabungan yang lebih baik, sehingga akan menghasilkan desain profil/elemen yang lebih ekonomis [4].

Struktur komposit pada aplikasinya merupakan elemen dari bangunan itu sendiri, baik sebagai kolom, balok ataupun pelat [4]. Kolom komposit terdiri dari 2 macam yaitu: kolom baja terbungkus beton (encased steel section) dan kolom baja berongga berisi beton (concrete filled tube). Balok komposit terdiri dari 2 macam yaitu: balok baja terbungkus beton dan balok baja dengan penghubung geser, baik menggunakan steel deck ataupun tidak. Penghubung geser (shear connector) menjadi penentu terjadinya aksi komposit pada balok komposit, penggunaan shear connector bertujuan untuk menjamin terjadinya interaksi mekanis antara baja dan beton, dan mengurangi terjadiya slip pada pelat beton dan balok baja[5].

\section{B. Base Isolator Elastometric Rubber Bearing}

Base isolator elastomeric rubber bearing dibentuk dari lembaran baja yang tipis dan karet yang disusun berlapis dan disatukan dengan cara vulkanisasi. Sistem ini bekerja dengan menjaga struktur diatasnya sebagai satu kesatuan. Pada saat terjadi gempa, masing-masing struktur bangunan akan bergetar akibat dari pergerakan tanah yang mempengaruhi pondasi bangunan. Karena pergerakan tanah yang terjadi bersifat acak maka getaran yang memasuki struktur juga tidak selaras, hal ini menyebabkan bangunan yang bersifat kaku mudah runtuh. Pada bangunan yang menggunakan base isolator, getaran yang terjadi pada pondasi akan melewati bantalan karet terlebih dahulu sebelum memasuki sistem struktur. Karena karet bersifat elastis maka arah getaran yang terjadi secara acak hanya akan mempengaruhi base isolator, sedangkan struktur diatasnya akan bergetar atau bergerak sebagai satu kesatuan struktur [6]. Perbandingan perilaku gedung tanpa dan dengan menggunakan base isolator dapat diilihat pada Gambar 1.

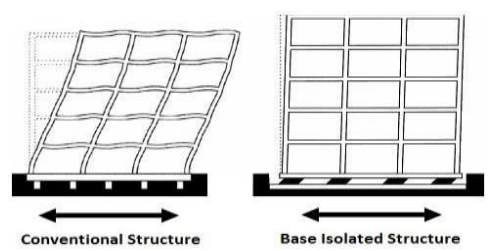

Gambar 1. Perbandingan Perilaku Gedung Menggunakan Base Isolator dan Fixed Base.

Prinsip utama cara kerja elastomeric adalah dengan memperpanjang waktu getar alami struktur diluar frekuensi dominan gempa sampai 2,5 atau 3 kali dari waktu getar struktur tanpa isolator (fixed base structure) dan memiliki damping antara $10 \%$ - 20\% sehingga gaya gempa yang disalurkan ke struktur lebih kecil [6].

High damping rubber bearing merupakan bahan anti seismik yang dikembangkan dari karet alam yang mempunyai kekakuan horizontal yang relatif kecil dan dicampur dengan extra fine carbon block, oil atau resin, serta bahan isian lainnya sehingga meningkatkan damping antara $10 \%$ - $20 \%$ pada shear strain $100 \%$ dengan modulus geser soft $(\mathrm{G}=0,4 \mathrm{MPa})$ dan hard $(\mathrm{G}=1,4 \mathrm{MPa})$ [6]. Base
Isolator High Damping Rubber Bearing dapat dilihat pada Gambar 2.

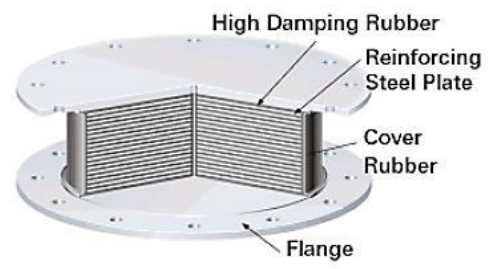

Gambar 2. Base Isolator High Damping Rubber Bearing.

\section{METODOLOGI}

\section{A. Bagan Alir Penyelesaian Studi}

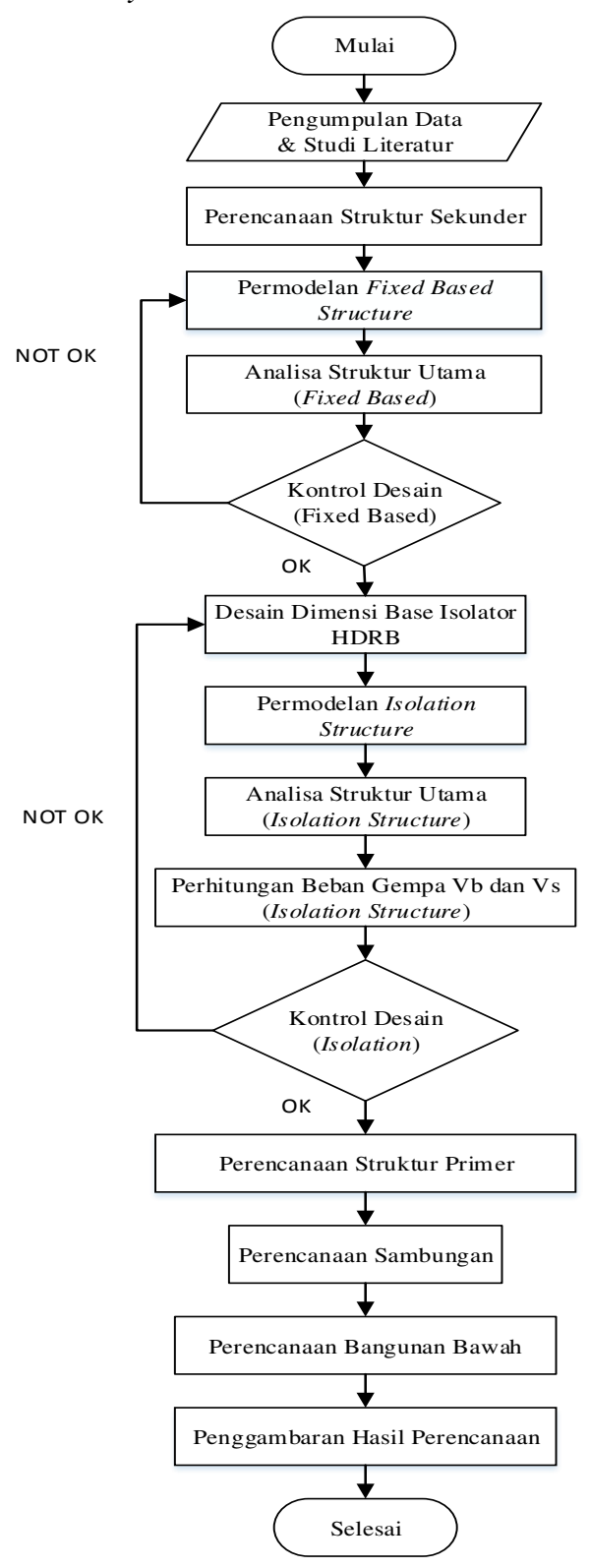

Gambar 3. Diagram Alir Penulisan Studi.

\section{B. Data Perencanaan}

Data modifikasi perencanaan pada Studi ini adalah sebagai berikut:

- Nama Gedung = One East Residence

- Lokasi = Jl. Kertajaya indah No. 79 Surabaya

- Fungsi = Apartemen

- Jumlah Lantai $=23$ Lantai

- Tinggi Gedung $=77,5 \mathrm{~m}$ 


$$
\begin{array}{ll}
\text { - Mutu Baja } & =\text { BJ } 41 \\
\text { - Mutu Beton } & =\mathrm{f}^{\prime} \mathrm{c} 30 \mathrm{Mpa} \\
\text { - Pondasi } & =\text { Tiang Bored Pile } \varnothing 80 \mathrm{~cm}
\end{array}
$$

- Struktur menggunakan material komposit baja beton (kolom profil hollow steel tube berintikan beton (concrete filled tube) dan balok komposit menggunakan shear connector dan steel deck) dengan base isolator tipe High Damping Rubber Bearing (HDRB).

- Sistem struktur adalah SRPMK

\section{ANALISA DAN HASIL}

\section{A. Perhitungan Struktur Sekunder}

Perhitungan struktur sekunder meliputi pelat, balok anak, tangga dan balok lift [7][8][9].

1) Pelat

Perencanaan pelat lantai atap dan lantai apartemen pada Studi ini menggunakan steel deck dari "Super Floor Deck" dengan tebal $0,75 \mathrm{~mm}$. Hasil perhitungan dapat dilihat pada Tabel 1 .

\begin{tabular}{|c|c|c|c|c|c|}
\hline $\begin{array}{l}\text { Jenis } \\
\text { Pelat }\end{array}$ & $\begin{array}{c}\text { Beban } \\
\text { Berguna } \\
\left(\mathrm{kg} / \mathrm{m}^{2}\right)\end{array}$ & $\begin{array}{c}\text { Bentang } \\
\text { (m) }\end{array}$ & $\begin{array}{l}\text { Tebal } \\
(\mathrm{cm})\end{array}$ & $\begin{array}{c}\text { Tulangan } \\
\text { Negatif } \\
\left(\mathrm{cm}^{2} / \mathrm{m}\right)\end{array}$ & Tulangan \\
\hline Atap & 154,9 & 2 & 9 & 1,07 & $\varnothing 8-300$ \\
\hline Lantai & 283,79 & 2 & 9 & 1,31 & $\varnothing 8-300$ \\
\hline
\end{tabular}

Tabel 1.

Dimensi dan Penulangan Pelat

2) Balok Anak

Balok anak pada Studi ini menggunakan profil WF dengan mutu baja BJ 41. Hasil perhitungan balok anak lantai atap dan lantai apartemen dapat dilihat pada Tabel 2.

Tabel 2.

Dimensi Balok Anak

\begin{tabular}{cccc}
\hline \hline \multicolumn{4}{c}{ Perencanan Balok Anak Lantai Atap \& Apartemen } \\
$\begin{array}{c}\text { Panjang (L) } \\
(\mathrm{m})\end{array}$ & Fy (Mpa) & Fu (Mpa) & Profil \\
\hline 4 & 250 & 410 & WF 200x150x6x9 \\
8 & 250 & 410 & WF 350x250x9x14 \\
10 & 250 & 410 & WF 450x300x11x18 \\
\hline \hline
\end{tabular}

\section{3) Tangga}

Berikut ini adalah data teknis perencanaan tangga lantai dasar pada Studi ini:

- Tinggi antar lantai $=4 \mathrm{~m}$

- Tinggi bordes $=2 \mathrm{~m}$

- Tinggi injakan $=20 \mathrm{~cm}$

- Lebar injakan $=25 \mathrm{~cm}$

- Jumlah injakan $=10$ buah

- Lebar bordes $=1,5 \mathrm{~m}$

- Panjang bordes $=3 \mathrm{~m}$

- Lebar tangga $=1,35 \mathrm{~m}$

- Panjang tangga $=2,5 \mathrm{~m}$

- Kemiringan $(\alpha)=38,7^{\circ}$

Hasil perhitungan perencanaan tangga lantai dasar dapat dilihat pada Tabel 3 dan Tabel 4 .

\begin{tabular}{|c|c|c|c|c|c|}
\hline $\begin{array}{l}\text { Jenis } \\
\text { Pelat }\end{array}$ & $\begin{array}{c}\text { Beban } \\
\text { Berguna } \\
\left(\mathrm{kg} / \mathrm{m}^{2}\right)\end{array}$ & $\begin{array}{c}\text { Bentang } \\
\text { (m) }\end{array}$ & $\begin{array}{l}\text { Tebal } \\
(\mathrm{cm})\end{array}$ & $\begin{array}{c}\text { Tulangan } \\
\text { Negatif } \\
\left(\mathrm{cm}^{2} / \mathrm{m}\right)\end{array}$ & Tulangan \\
\hline Tangga & 569,45 & 1,35 & 9 & 1,11 & $\varnothing 8-300$ \\
\hline Bordes & 533,45 & 1,35 & 9 & 1,11 & $\varnothing 8-300$ \\
\hline
\end{tabular}

Tabel 3.

Rekapitulasi Perhitungan Pelat Tangga Lt. Dasar

Tabel 4.

Rekapitulasi Perhitungan Balok Utama \& Penumpu Tangga Lt. Dasar Perencanaan Balok Utama \& Penumpu Tangga Lt. Dasar BJ 41

\begin{tabular}{|c|c|c|c|}
\hline Utama & 250 & 410 & WF $200 \times 150 \times 6 \times 9$ \\
\hline Penumpu & 250 & 410 & WF $200 \times 150 \times 6 \times 9$ \\
\hline
\end{tabular}

Fy (Mpa)

Fu (Mpa)
4) Balok Lift

Pada Studi ini, spesifikasi lift menggunakan produk "Sigma Elevator Company" dengan kapasitas 24 Orang (1600 kg), 1 car dan dengan kecepatan 1m/s. Didapatkan dimensi balok penggantung lift adalah WF 400x300x10x16. B. Analisa Struktur Fixed Base

Hasil dari analisa struktur fixed base ini adalah waktu getar alami fundamental struktur dan reaksi pada kolom yang akan digunakan untuk perencanaan isolation structure dan perencanaan dimensi base isolator.

1) Kontrol Pembebanan Gravitasi

Berdasarkan hasil perhitungan SAP 2000 dengan kombinasi pembebanan (1D+1L) didapatkan beban struktur adalah $38027148,17 \mathrm{~kg}$, dan berdasarkan hasil perhitungan manual didapatkan beban struktur adalah $37064684,02 \mathrm{~kg}$. Berdasarkan hasil tersebut didapatkan selisih pembebanan sebesar 2,5309\% sehingga memenuhi toleransi < 5\%[9] [10].

2) Kontrol Waktu Getar Alami Fundamental

Pada Studi ini didapatkan nilai Ta sebesar 1,268 detik dan nilai $\mathrm{Cu}=1,4$. Sehingga batas atas dari periode getar alami fundamental adalah:

$\mathrm{T}=\mathrm{Cu} \times \mathrm{Ta}=1,4 \times 1,268=1,778$ detik.

Berdasarkan hasil analisa SAP 2000 didapatkan periode sebesar 3,946 detik. Karena Ta SAP $2000=3,946 \mathrm{dt}>\mathrm{T}=$ $\mathrm{Cu} \times \mathrm{Ta}=1,778 \mathrm{dt}$ maka selanjutnya dalam desain struktur fixed base digunakan $\mathrm{Ta}=1,778$ detik [11].

3) Kontrol Gaya Geser Dasar (Base Shear)

Apabila kombinasi respon dinamik (Vt) lebih kecil dari $85 \%$ dari gaya geser statik ekivalen (Vs) maka gaya harus dikalikan $0,85 \mathrm{~V} / \mathrm{Vt}$ [11]. Total berat bangunan adalah $32828860,39 \mathrm{~kg}$ [9][10]. Nilai V statik (Vs) didapat dengan rumusan: [3]

$$
\begin{aligned}
\mathrm{Vs} & =\mathrm{Cs} \times \mathrm{W} \\
& =0,0349 \times 32828860,39 \mathrm{~kg} \\
& =1146068,511 \mathrm{~kg} \\
0,85 \mathrm{Vs} & =0,85 \times 1146068,511 \mathrm{~kg} \\
& =916854,8089 \mathrm{~kg} .
\end{aligned}
$$

\begin{tabular}{|c|c|c|}
\hline Arah Gempa & Beban Gempa (kgf) & $\mathrm{Vt} \geq 0,85 \mathrm{Vs}$ \\
\hline Arah X & 1034977,65 & $\mathrm{OK}$ \\
\hline Arah Y & 861324,88 & NOT OK \\
\hline
\end{tabular}

Berdasarkan hasil analisa SAP 2000, didapatkan gaya gempa dinamis seperti pada Tabel 5.

Tabel 5.

Gaya Gempa Dinamis (Vt) Struktur Fixed Base

Karena Vt masih kurang dari $0,85 \mathrm{Vs}$, maka gaya gempa perlu dikalikan faktor skala [11]. Faktor skala gempa arah X adalah 0,9412 dan faktor skala gempa arah Y dalah 1,1309.

Besar gaya gempa dinamis setelah dikalikan faktor skala dapat dilihat pada Tabel 6.

Tabel 6.

Gaya Gempa Dinamis (Vt) Struktur Fixed Base Skala

\begin{tabular}{ccc}
\hline \hline Arah Gempa & Beban Gempa (kgf) & Vt $\geq 0,85 \mathrm{Vs}$ \\
\hline Arah X & 1194571,2 & OK \\
Arah Y & 1194561,53 & OK \\
\hline
\end{tabular}

Berdasarkan hasil tersebut, maka memenuhi persyaratan [11].

4) Kontrol Partisipasi Massa

Berdasarkan hasil analisa SAP 2000, didapatkan partisipasi massa pada arah X sebesar $91,5 \%$ pada mode ke 9 dan partisipasi massa pada arah Y sebesar $90,9 \%$ pada 
mode ke 7. Berdasarkan hasil tersebut, maka memenuhi syarat $\geq 90 \%[11]$

5) Kontrol Simpangan Antar Lantai (Drift)

Simpangan antar lantai (Drift) dihitung sebagai perbedaan deleksi pada pusat massa bangunan pada tingkat atas dan bawah pada lantai yang di tinjau. Kontrol simpangan arah $\mathrm{X}$ dapat dilihat pada Tabel. 7 dan Kontrol simpangan arah Y dapat dilihat pada Tabel 8 .

Tabel 7.

Kontrol Simpangan Antar Lantai arah X Struktur Fixed Base

\begin{tabular}{ccccccc}
\hline \hline Tingkat & hi & $\begin{array}{c}\delta \mathrm{xe} \\
\mathrm{mm}\end{array}$ & $\begin{array}{c}\delta \mathrm{x} \\
\mathrm{mm}\end{array}$ & $\begin{array}{c}\Delta \\
\mathrm{mm}\end{array}$ & $\begin{array}{c}\Delta \mathrm{a} \\
\mathrm{mm}\end{array}$ & $\Delta \leq \Delta \mathrm{a}$ \\
\hline Atap & 3.5 & 124.11 & 682.63 & 7.38 & 70 & OKE \\
Lt 21 & 3.5 & 122.77 & 675.24 & 10.70 & 70 & OKE \\
Lt 20 & 3.5 & 120.83 & 664.54 & 14.32 & 70 & OKE \\
Lt 19 & 3.5 & 118.22 & 650.22 & 17.79 & 70 & OKE \\
Lt 18 & 3.5 & 114.99 & 632.44 & 21.01 & 70 & OKE \\
Lt 17 & 3.5 & 111.17 & 611.43 & 23.99 & 70 & OKE \\
Lt 16 & 3.5 & 106.81 & 587.44 & 26.83 & 70 & OKE \\
Lt 15 & 3.5 & 101.93 & 560.61 & 28.36 & 70 & OKE \\
Lt 14 & 3.5 & 96.77 & 532.25 & 30.58 & 70 & OKE \\
Lt 13 & 3.5 & 91.21 & 501.67 & 32.78 & 70 & OKE \\
Lt 12 & 3.5 & 85.25 & 468.90 & 34.89 & 70 & OKE \\
Lt 11 & 3.5 & 78.91 & 434.00 & 36.94 & 70 & OKE \\
Lt 10 & 3.5 & 72.19 & 397.06 & 38.94 & 70 & OKE \\
Lt 9 & 3.5 & 65.11 & 358.12 & 40.99 & 70 & OKE \\
Lt 8 & 3.5 & 57.66 & 317.13 & 40.81 & 70 & OKE \\
Lt 7 & 3.5 & 50.24 & 276.32 & 42.31 & 70 & OKE \\
Lt 6 & 3.5 & 42.55 & 234.01 & 43.77 & 70 & OKE \\
Lt 5 & 3.5 & 34.59 & 190.24 & 44.92 & 70 & OKE \\
Lt 4 & 3.5 & 26.42 & 145.32 & 45.30 & 70 & OKE \\
Lt 3 & 3.5 & 18.18 & 100.01 & 43.91 & 70 & OKE \\
Lt 2 & 3.5 & 10.20 & 56.10 & 42.42 & 70 & OKE \\
Lt 1 & 4 & 2.49 & 13.68 & 13.68 & 80 & OKE \\
Lt BI & 2 & 0 & 0 & 0 & 0 & - \\
\hline \hline
\end{tabular}

Tabel 8.

Kontrol Simpangan Antar Lantai arah Y Struktur Fixed Base

\begin{tabular}{ccccccc}
\hline \hline Tingkat & $\begin{array}{c}\text { hi } \\
\mathrm{m}\end{array}$ & $\begin{array}{c}\delta \mathrm{xe} \\
\mathrm{mm}\end{array}$ & $\begin{array}{c}\delta \mathrm{x} \\
\mathrm{mm}\end{array}$ & $\begin{array}{c}\Delta \\
\mathrm{mm}\end{array}$ & $\begin{array}{c}\Delta \mathrm{a} \\
\mathrm{mm}\end{array}$ & $\Delta \leq \Delta \mathrm{a}$ \\
\hline Atap & 3.5 & 41.05 & 225.77 & 2.56 & 70 & OKE \\
Lt 21 & 3.5 & 40.58 & 223.20 & 3.17 & 70 & OKE \\
Lt 20 & 3.5 & 40.01 & 220.03 & 4.37 & 70 & OKE \\
Lt 19 & 3.5 & 39.21 & 215.66 & 5.54 & 70 & OKE \\
Lt 18 & 3.5 & 38.20 & 210.12 & 6.63 & 70 & OKE \\
Lt 17 & 3.5 & 37.00 & 203.49 & 7.66 & 70 & OKE \\
Lt 16 & 3.5 & 35.61 & 195.83 & 8.67 & 70 & OKE \\
Lt 15 & 3.5 & 34.03 & 187.17 & 9.30 & 70 & OKE \\
Lt 14 & 3.5 & 32.34 & 177.86 & 10.07 & 70 & OKE \\
Lt 13 & 3.5 & 30.51 & 167.79 & 10.86 & 70 & OKE \\
Lt 12 & 3.5 & 28.53 & 156.93 & 11.61 & 70 & OKE \\
Lt 11 & 3.5 & 26.42 & 145.32 & 12.35 & 70 & OKE \\
Lt 10 & 3.5 & 24.18 & 132.98 & 13.07 & 70 & OKE \\
Lt 9 & 3.5 & 21.80 & 119.91 & 13.82 & 70 & OKE \\
Lt 8 & 3.5 & 19.29 & 106.09 & 13.96 & 70 & OKE \\
Lt 7 & 3.5 & 16.75 & 92.13 & 14.45 & 70 & OKE \\
Lt 6 & 3.5 & 14.12 & 77.68 & 14.94 & 70 & OKE \\
Lt 5 & 3.5 & 11.41 & 62.74 & 15.28 & 70 & OKE \\
Lt 4 & 3.5 & 8.63 & 47.46 & 15.28 & 70 & OKE \\
Lt 3 & 3.5 & 5.85 & 32.18 & 14.53 & 70 & OKE \\
Lt 2 & 3.5 & 3.21 & 17.65 & 13.47 & 70 & OKE \\
Lt 1 & 4 & 0.76 & 4.18 & 4.18 & 80 & OKE \\
Lt BI & 2 & 0 & 0 & 0 & 0 & - \\
\hline \hline
\end{tabular}

Berdasarkan hasil tersebut, maka simpangan antar lantai arah X dan Y memenuhi persyaratan [11].

\section{Analisa Struktur Isolasi}

Pada perencanaan struktur isolasi harus terdapat jalan akses untuk pemeriksaan dan penggantian semua komponen-komponen base isolator[11]. Pada Studi ini lantai pememliharaan base isolator direncanakan $2 \mathrm{~m}$.
Nilai $T_{M}=$ periode struktur isolasi dan nilai $T_{D}=3 x$ periode fixed base [11]. Berdasarkan hasil analisa SAP 2000 didapatkan $\mathrm{T}$ struktur isolasi $=5,725$ detik, sehingga $\mathrm{T}_{\mathrm{M}}=$ 5,725 detik dan $T_{D}=3 \times 1,775=5,325$ detik.

Nilai faktor reduksi gempa (R) pada struktur isolasi adalah 2, untuk faktor keutamaan gempa (I) $=1$ [11]. Berdasarkan tipe base isolator yang dipilih pada brosur bridgestone didapat damping ratio $=0,24$ dengan nilai koefisien redaman $\mathrm{B}_{\mathrm{D}}$ atau $\mathrm{B}_{\mathrm{M}}=1,58$ (interpolasi linier) [11].

1) Dimensi Base Isolator HDRB

Pada analisa struktur fixed base didapatkan gaya aksial kolom interior terbesar (m) adalah $20729,3701 \mathrm{kN}$ kgf dan kolom eksterior terbesar (m) adalah $14097,524 \mathrm{kN}$.

Pada perhitungan dimensi base isiolator [12], berdasarkan brosur bridgestone, dipilih base isolator dengan spesifikasi:

a) $\operatorname{Modulus}$ Shear $(\mathrm{G})=0,620 \mathrm{MN} / \mathrm{m}^{2}$

b) Ketebalan Rubber (tr) $=200 \mathrm{~mm}$

- Menghitung kekakuan horizontal $\left(\mathrm{K}_{\mathrm{H}}\right)$ :

$K_{H}=\frac{m x\left(\frac{2 \pi}{T_{D}}\right)}{\text { Pjg.bentang }}=\frac{20,729 M N x\left(\frac{2 \pi}{5,325}\right)^{2}}{10 m}$

$K_{H}=2,886 \mathrm{MN} / \mathrm{m}$

Hasil perhitungan kekakuan horizontal base isolator [12] interior \& eksterior dapat dilihat pada Tabel 9.

Tabel 9.

Kekakuan Horizontal (KH) Base Isolator Interior \& Eksterior

\begin{tabular}{ccc}
\hline \hline Base Isolator & Gaya Aksial $(\mathrm{m})$ & Kekauan $\left(\mathrm{K}_{\mathrm{H}}\right)$ \\
\hline Interior & $20,729 \mathrm{MN}$ & $2,886 \mathrm{MN} / \mathrm{m}$ \\
Eksterior & $14,097 \mathrm{MN}$ & $1,962 \mathrm{MN} / \mathrm{m}$ \\
\hline \hline
\end{tabular}

- Menghitung luasan rubber (A):

$A=\frac{K_{H} \times t r}{G}=\frac{2,886 \times 0,2}{0,620}=0,9309 \mathrm{~m}^{2}$

Hasil perhitungan luasan rubber base isolator [10] interior \& eksterior dapat dilihat pada Tabel 10.

Tabel 10.

Luasan Rubber (A) Base Isolator Interior \& Eksterior

\begin{tabular}{ccc}
\hline \hline Base Isolator & Kekakuan $\left(\mathrm{K}_{\mathrm{H}}\right)$ & Luas Rubber $(\mathrm{A})$ \\
\hline Interior & $2,886 \mathrm{MN} / \mathrm{m}$ & $0,9309 \mathrm{~m}^{2}$ \\
Eksterior & $1,962 \mathrm{MN} / \mathrm{m}$ & $0,6331 \mathrm{~m}^{2}$ \\
\hline \hline
\end{tabular}

- Menghitung diameter rubber (D):

$A=\frac{1}{4} x \pi \times D^{2} \rightarrow D=\sqrt{\frac{4 A}{\pi}}=\sqrt{\frac{4 \times 0,9309}{\pi}}=1,088 \mathrm{~m}$ Hasil perhitungan diameter rubber base isolator [12] interior \& eksterior dapat dilihat pada Tabel 11.

Tabel 11.

Diameter Rubber (D) Base Isolator Interior \& Eksterior

\begin{tabular}{ccc}
\hline \hline Base Isolator & Luas Rubber (A) & Diameter Rubber (D) \\
\hline Interior & $0,9309 \mathrm{~m}^{2}$ & $1,088 \mathrm{~m}$ \\
Eksterior & $0,6331 \mathrm{~m}^{2}$ & $0,8978 \mathrm{~m}$ \\
\hline \hline
\end{tabular}

Berdasarkan hasil tersebut maka untuk base isolator interior digunakan HDRB HH 110 x 6R dan base isolator eksterior menggunakan HDRB HH 90 x 6R.

2) Kontrol Simpangan Antar Lantai (Drift)

Simpangan antar lantai maksimum dari struktur diatas sistem isolasi yang dihitung dengan analisis spektrum respon tidak boleh melebihi $0,015 \mathrm{~h}_{\mathrm{sx}}$, dengan nilai faktor Cd sama dengan nilai faktor R [11]. Kontrol simpangan arah 
X dapat dilihat pada Tabel. 12 dan Kontrol simpangan arah

Y dapat dilihat pada Tabel 13.

Berdasarkan hasil tersebut, maka simpangan antar lantai arah X dan Y memenuhi persyaratan [11].

3) Kontrol Perpindahan Base Isolator

- Menghitung perpindahan maksimum base isolator:

$D M=\frac{g \times S_{M 1 \times} T_{D}}{4 \pi^{2} \times B_{M}}=\frac{9810 \times 0,743 \times 5,725}{4 \pi^{2} \times 1,58}=669,9 \mathrm{~mm}$

Tabel 12.

Kontrol Simpangan Antar Lantai arah X Struktur Isolasi

\begin{tabular}{ccccccc}
\hline \hline Tingkat & hi & $\begin{array}{c}\delta x \mathrm{x} \\
\mathrm{m}\end{array}$ & $\begin{array}{c}\delta \mathrm{x} \\
\mathrm{mm}\end{array}$ & $\begin{array}{c}\Delta \\
\mathrm{mm}\end{array}$ & $\begin{array}{c}\Delta \mathrm{a} \\
\mathrm{mm}\end{array}$ & $\Delta \leq \Delta \mathrm{a}$ \\
\hline Atap & 3.5 & 417.82 & 835.64 & 3.02 & 45 & OKE \\
Lt 21 & 3.5 & 416.31 & 832.62 & 4.52 & 45 & OKE \\
Lt 20 & 3.5 & 414.05 & 828.10 & 6.26 & 45 & OKE \\
Lt 19 & 3.5 & 410.92 & 821.84 & 8.04 & 45 & OKE \\
Lt 18 & 3.5 & 406.90 & 813.80 & 9.80 & 45 & OKE \\
Lt 17 & 3.5 & 402.00 & 804.00 & 11.54 & 45 & OKE \\
Lt 16 & 3.5 & 396.23 & 792.46 & 13.27 & 45 & OKE \\
Lt 15 & 3.5 & 389.59 & 779.19 & 14.29 & 45 & OKE \\
Lt 14 & 3.5 & 382.45 & 764.90 & 15.78 & 45 & OKE \\
Lt 13 & 3.5 & 374.56 & 749.12 & 17.27 & 45 & OKE \\
Lt 12 & 3.5 & 365.92 & 731.85 & 18.74 & 45 & OKE \\
Lt 11 & 3.5 & 356.55 & 713.11 & 20.18 & 45 & OKE \\
Lt 10 & 3.5 & 346.46 & 692.93 & 21.61 & 45 & OKE \\
Lt 9 & 3.5 & 335.66 & 671.32 & 23.07 & 45 & OKE \\
Lt 8 & 3.5 & 324.13 & 648.25 & 22.93 & 45 & OKE \\
Lt 7 & 3.5 & 312.66 & 625.32 & 24.06 & 45 & OKE \\
Lt 6 & 3.5 & 300.63 & 601.26 & 25.25 & 45 & OKE \\
Lt 5 & 3.5 & 288.01 & 576.01 & 26.43 & 45 & OKE \\
Lt 4 & 3.5 & 274.79 & 549.58 & 27.57 & 45 & OKE \\
Lt 3 & 3.5 & 261.00 & 522.01 & 28.59 & 45 & OKE \\
Lt 2 & 3.5 & 246.71 & 493.42 & 33.03 & 45 & OKE \\
Lt 1 & 4 & 230.20 & 460.39 & 21.20 & 60 & OKE \\
Lt BI & 2 & 219.59 & 439.19 & - & - & - \\
\hline \hline
\end{tabular}

Tabel 13.

Kontrol Simpangan Antar Lantai arah Y Struktur Isolasi

\begin{tabular}{ccccccc}
\hline \hline Tingkat & $\begin{array}{c}\text { hi } \\
\mathrm{m}\end{array}$ & $\begin{array}{c}\delta \mathrm{xe} \\
\mathrm{mm}\end{array}$ & $\begin{array}{c}\delta \mathrm{x} \\
\mathrm{mm}\end{array}$ & $\begin{array}{c}\Delta \\
\mathrm{mm}\end{array}$ & $\begin{array}{c}\Delta \mathrm{a} \\
\mathrm{mm}\end{array}$ & $\Delta \leq \Delta \mathrm{a}$ \\
\hline Atap & 3.5 & 122.98 & 676.41 & 3.10 & 45 & OKE \\
Lt 21 & 3.5 & 122.42 & 673.31 & 3.87 & 45 & OKE \\
Lt 20 & 3.5 & 121.72 & 669.44 & 5.22 & 45 & OKE \\
Lt 19 & 3.5 & 120.77 & 664.22 & 6.59 & 45 & OKE \\
Lt 18 & 3.5 & 119.57 & 657.63 & 7.95 & 45 & OKE \\
Lt 17 & 3.5 & 118.12 & 649.68 & 9.29 & 45 & OKE \\
Lt 16 & 3.5 & 116.43 & 640.39 & 10.62 & 45 & OKE \\
Lt 15 & 3.5 & 114.50 & 629.77 & 11.36 & 45 & OKE \\
Lt 14 & 3.5 & 112.44 & 618.41 & 12.48 & 45 & OKE \\
Lt 13 & 3.5 & 110.17 & 605.93 & 13.62 & 45 & OKE \\
Lt 12 & 3.5 & 107.69 & 592.30 & 14.74 & 45 & OKE \\
Lt 11 & 3.5 & 105.01 & 577.56 & 15.83 & 45 & OKE \\
Lt 10 & 3.5 & 102.13 & 561.73 & 16.91 & 45 & OKE \\
Lt 9 & 3.5 & 99.06 & 544.82 & 18.02 & 45 & OKE \\
Lt 8 & 3.5 & 95.78 & 526.80 & 17.79 & 45 & OKE \\
Lt 7 & 3.5 & 92.55 & 509.01 & 18.61 & 45 & OKE \\
Lt 6 & 3.5 & 89.16 & 490.40 & 19.50 & 45 & OKE \\
Lt 5 & 3.5 & 85.62 & 470.90 & 20.40 & 45 & OKE \\
Lt 4 & 3.5 & 81.91 & 450.50 & 21.26 & 45 & OKE \\
Lt 3 & 3.5 & 78.04 & 429.25 & 22.06 & 45 & OKE \\
Lt 2 & 3.5 & 74.03 & 407.19 & 25.53 & 45 & OKE \\
Lt 1 & 4 & 69.39 & 381.66 & 16.23 & 60 & OKE \\
Lt BI & 2 & 66.44 & 365.43 & - & - & - \\
\hline \hline
\end{tabular}

Berdasarkan hasil perhitungan tersebut, maka perpindahan base isolator pada arah X adalah 439,187 mm $\leq 669,9 \mathrm{~mm}(\mathrm{OK})$ dan perpindahan base isolator pada arah $\mathrm{Y}$ adalah $365,425 \mathrm{~mm} \leq 669,9 \mathrm{~mm}(\mathrm{OK})$. Jadi perpindahan base isolator telah memenuhi persyaratan [11].

4) Kontrol Gaya Geser Dasar (Base Shear)

Gaya geser statik (Vs) untuk elemen struktur diatas sistem isolasi [3] adalah

$V s=\frac{K_{D \max } \times D_{D}}{R}=\frac{66695,44 \mathrm{kN} / \mathrm{m} \times 0,415 \mathrm{~m}}{2}$

$=13851,5591 \mathrm{kN}=1385155,91 \mathrm{Kg}$

Gaya gempa dinamis $\geq 0,85 \mathrm{Vs}=1108124,73 \mathrm{~kg}$ [11]. Berdasarkan hasil analisa SAP 2000, didapatkan gaya gempa dinamis seperti pada Tabel 14 .

Tabel 14 .

Gaya Gempa Dinamis Struktur Isolasi

\begin{tabular}{ccc}
\hline \hline Arah Gempa & Beban Gempa (kgf) & Vt $\geq 0,85 \mathrm{Vs}$ \\
Arah X & 1891880.12 & OK \\
\hline Arah Y & 1902237.64 & OK \\
\hline \hline
\end{tabular}

Berdasarkan hasil tersebut, maka memenuhi persyaratan [11].

4) Kontrol Partisipasi Massa

Berdasarkan hasil analisa SAP 2000, didapatkan partisipasi massa pada arah X sebesar $96,6 \%$ pada mode ke 2 dan partisipasi massa pada arah Y sebesar 96,7\% pada mode ke 3. Berdasarkan hasil tersebut, maka memenuhi syarat $\geq 90 \%$ [11].

\section{Perhitungan Struktur Primer}

Struktur Primer menggunakan struktur komposit dimana balok induk komposit dengan shear connector dan steel deck, dan kolom komposit baja berisi beton (concrete filled tube).

1) Balok Induk

Hasil perhitungan [8] balok induk dapat dilihat pada Tabel 15 .

Tabel 15.

Rekapitulasi Perhitungan Balok Induk

\begin{tabular}{ccccc}
\hline \hline \multicolumn{5}{c}{ Perencanaan Balok Induk } \\
\hline$(\mathrm{L})$ & BJ 41 (Mpa) & Profil & Arah \\
$\mathrm{m}$ & Fy & Fu & WF 350x250x9x14 & Memanjang \\
4 & 250 & 410 & WF 700x300x13x24 & Memanjang \\
8 & 250 & 410 & WF 800x300x14x26 & Memanjang \\
10 & 250 & 410 & WF 800x300x14x26 & Melintang \\
10 & 250 & 410 & & \\
\hline \hline
\end{tabular}

2) Kolom

Hasil perhitungan [8] kolom dapat dilihat pada Tabel 16.

Tabel 16

Rekapitulasi Perhitungan Kolom

\begin{tabular}{ccccc}
\hline \hline & \multicolumn{4}{c}{ Perencanaan Kolom } \\
Lantai & Tinggi & \multicolumn{2}{c}{ BJ 41 (Mpa) } & Profil \\
& $(\mathrm{m})$ & Fy & Fu & \\
\hline Lt 1-8 & 3,5 & 250 & 410 & HSS 700x700x28 \\
Lt 8-15 & 3,5 & 250 & 410 & HSS 600x600x25 \\
Lt 15-Atap & 3,5 & 250 & 410 & HSS 550x550x25 \\
\hline \hline
\end{tabular}

\section{E. Perhitungan Sambungan}

1) Sambungan Balok Anak Lantai Atap \& Lantai Apartemen dengan Balok Induk.

Sambungan direncanakan sebagai simple connection. Sambungan menggunakan baut mutu fub $=5000 \mathrm{~kg} / \mathrm{cm}^{2}$. Hasil perhitungan sambungan balok anak - balok induk [13], [14] dapat dilihat pada Tabel 17. 


\begin{tabular}{cccc}
\hline \hline Sambungan & Elemen & Pelat Penyambung & Baut \\
\hline \multirow{2}{*}{ BA L $=4 \mathrm{~m} \&$ BI } & Badan BA & L $60 \times 60 \times 6$ & $2 \varnothing 10$ \\
& Badan BI & L $60 \times 60 \times 6$ & $2 \varnothing 10$ \\
BA L $=8 \mathrm{~m} \&$ BI & Badan BA & L $60 \times 60 \times 6$ & $3 \varnothing 10$ \\
& Badan BI & L $60 \times 60 \times 6$ & $3 \varnothing 10$ \\
BA L $=10 \mathrm{~m} \&$ BI & Badan BA & L $60 \times 60 \times 6$ & $3 \varnothing 10$ \\
& Badan BI & L $60 \times 60 \times 6$ & $3 \varnothing 10$ \\
\hline
\end{tabular}

2) Sambungan Balok Induk - Kolom

Sambungan direncanakan sebagai rigid connection (las \& baut). Sambungan ini menggunakan baut mutu tinggi A 325 pada badan balok, baut mutu tinggi A 490 pada sayap balok dan Las $\mathrm{F}_{\mathrm{E}} 110 \mathrm{xx}$. Hasil perhitungan sambungan balok induk - kolom [13], [14] dapat dilihat pada Tabel 18.

Tabel 18.

Rekapitulasi Sambungan Balok Induk - Kolom

\begin{tabular}{|c|c|c|c|}
\hline Sambungan & Elemen & $\begin{array}{c}\text { Pelat } \\
\text { Penyambung }\end{array}$ & Baut / Las \\
\hline \multirow{5}{*}{$\begin{array}{c}\text { BI L= 4m \& } \\
\text { Kolom }\end{array}$} & Badan BI & Pelat $14 \mathrm{~mm}$ & A $3253 \varnothing 20$ \\
\hline & Badan BI & Pelat $14 \mathrm{~mm}$ & Las $\mathrm{F}_{\mathrm{E}} 110 \mathrm{xx} 16 \mathrm{~mm}$ \\
\hline & Sayap A BI & Pelat $26 \mathrm{~mm}$ & A $4906 \varnothing 24$ \\
\hline & Sayap B BI & Pelat $26 \mathrm{~mm}$ & A $4906 \varnothing 24$ \\
\hline & Kolom & Pelat $26 \mathrm{~mm}$ & Las $\mathrm{F}_{\mathrm{E}} 110 \mathrm{xx} 25 \mathrm{~mm}$ \\
\hline \multirow{6}{*}{$\begin{array}{c}\text { BI L }=8 \mathrm{~m} \& \\
\text { Kolom }\end{array}$} & Badan BI & Pelat $14 \mathrm{~mm}$ & A $3256 \varnothing 20$ \\
\hline & Badan BI & Pelat $14 \mathrm{~mm}$ & Las $F_{\mathrm{E}} 110 \mathrm{xx} 20 \mathrm{~mm}$ \\
\hline & Sayap A BI & Pelat $26 \mathrm{~mm}$ & A $49012 \varnothing 24$ \\
\hline & Sayap B BI & Pelat $26 \mathrm{~mm}$ & A $49012 \varnothing 24$ \\
\hline & Kolom & Pelat $26 \mathrm{~mm}$ & Las $\mathrm{F}_{\mathrm{E}} 110 \mathrm{xx} 25 \mathrm{~mm}$ \\
\hline & Badan BI & Pelat $14 \mathrm{~mm}$ & A $3256 \varnothing 20$ \\
\hline $\mathrm{BI} L=10 \mathrm{~m}$ & Badan BI & Pelat $14 \mathrm{~mm}$ & Las $\mathrm{F}_{\mathrm{E}} 110 \mathrm{xx} 20 \mathrm{~mm}$ \\
\hline Arah X \& & Sayap A BI & Pelat $26 \mathrm{~mm}$ & A $49012 \varnothing 24$ \\
\hline \multirow[t]{3}{*}{ Kolom } & Sayap B BI & Pelat $26 \mathrm{~mm}$ & A $49012 \not 24$ \\
\hline & Kolom & Pelat $26 \mathrm{~mm}$ & Las $F_{\mathrm{E}} 110 \mathrm{xx} 25 \mathrm{~mm}$ \\
\hline & Badan BI & Pelat $14 \mathrm{~mm}$ & A $3257 \varnothing 20$ \\
\hline $\mathrm{BI} L=10 \mathrm{~m}$ & Badan BI & Pelat $14 \mathrm{~mm}$ & Las $F_{\mathrm{E}} 110 \mathrm{xx} 20 \mathrm{~mm}$ \\
\hline Arah Y \& & Sayap A BI & Pelat $26 \mathrm{~mm}$ & A $49012 \varnothing 24$ \\
\hline \multirow[t]{2}{*}{ Kolom } & Sayap B BI & Pelat $26 \mathrm{~mm}$ & A $49012 \varnothing 24$ \\
\hline & Kolom & Pelat $26 \mathrm{~mm}$ & Las $F_{\mathrm{E}} 110 \times x 25 \mathrm{~mm}$ \\
\hline
\end{tabular}

\section{3) Sambungan Antar Kolom}

Sambungan antar kolom direncanakan dengan menggunakan Las Sudut $\mathrm{F}_{\mathrm{E}}$ 110xx dengan pelat tambahan. Hasil perhitungan sambungan antar kolom [13], [14] dapat dilihat pada Tabel 19 .

Tabel 19.

Rekapitulasi Sambungan Antar Kolom

\begin{tabular}{cccc}
\hline \hline Sambungan & Elemen & $\begin{array}{c}\text { Pelat } \\
\text { Penyambung }\end{array}$ & Baut / Las \\
\hline HSS 700x700x28 & Kolom & Pelat 65 mm & Las F $F_{\mathrm{E}} 110 \times x$ 29 mm \\
HSS 600x600x25 & Kolom & Pelat 50 mm & Las F F $110 \times x$ mm \\
HSS 550x550x25 & Kolom & Pelat 50 mm & Las F F $110 x x$ 11 mm \\
\hline \hline
\end{tabular}

4) Sambungan Balok Induk - Pedestal

Sambungan ini menggunakan jenis extended end plate tanpa pengaku dengan baut angkur A490 dengan hasil [2], [9] sebagai berikut:

- Sambungan Las Mutu $\mathrm{F}_{\mathrm{E}} 110 \mathrm{xx}$ dengan a= $1 \mathrm{~cm}$

- Sambungan baut angkur A 490, Panjang angkur $=500 \mathrm{~mm}$ 5) Sambungan Base Plate

Sambungan base plate direncanakan menggunakan Las \& Baut angkur dengan hasil [13], [14] sebagai berikut:

- Sambungan Las $F_{E} 110 x x$ dengan a $=29 \mathrm{~mm}$

- Baut Angkur F1554 grade 105 diameter Ø 20 mm dengan panjang angkur $500 \mathrm{~mm}$.

- Tebal base plate $\mathrm{t}=70 \mathrm{~mm}$.

F. Perhitungan Bangunan Bawah
Berdasarkan data tanah yang ada, pondasi direncanakan menggunakan tiang bored pile [15] dengan diameter $\varnothing 80$ $\mathrm{cm}$. Pondasi bored pile direncanakan dengan kedalaman 30 $\mathrm{m}$.

1) Pedestal

Pada Studi ini terdapat 2 jenis pedestal [16], yaitu:

- Pedestal tipe 1 (Kolom Eksterior)

Dimensi: 1250 x 1250 mm, Tulangan Utama: 32D25 dan

Tulangan Geser: D14-150 mm

- Pedestal tipe 2 (Kolom Interior)

Dimensi: 1500 x 1500 mm, Tulangan Utama: 40D28 dan

Tulangan Geser: D14-150 mm.

2) Pilecap

Pada Studi ini terdapat 2 jenis pilecap [5], [15],

yaitu:

- Pilecap tipe 1

Dimensi: 640 x 640 x $140 \mathrm{~cm}$, Jumlah bored pile: 9 buah, Tulangan Sisi Panjang: Atas ( D19-80) \& Bawah (D25-70), Tulangan Sisi Pendek: Atas ( D19-80) \& Bawah (D25-70). - Pilecap tipe 2

Dimensi: 960 × 640 x $110 \mathrm{~cm}$, Jumlah bored pile: 24 buah, Tulangan Sisi Panjang: Atas ( D19-340) \& Bawah (D25290), Tulangan Sisi Pendek: Atas (D19-340) \& Bawah (D25-290).

\section{3) Balok Sloof}

Berdasarkan perhitungan [5] didapatkan dimensi balok sloof adalah $450 \times 600 \mathrm{~mm}$. Dengan tulangan positif 2D16 dan tulangan negatif 5D16 pada sisi tumpuan, sedangkan tulangan positif 5D16 dan tulangan negatif 2D16 pada sisi lapangan. Selain itu, terdapat juga tulangan geser $\varnothing 10-250$ $\mathrm{mm}$.

\section{KESIMPULAN DAN SARAN}

\section{A. Kesimpulan}

Sesuai dengan tujuan penulisan Studi ini, maka dapat ditarik kesimpulan sebagai berikut:

1. Hasil perhitungan pada struktur sekunder telah memenuhi syarat terhadap kontrol kuat penampang, kuat geser dan lendutan.

2. Berdasarkan analisa struktur yang dilakukan (Kontrol waktu getar alami fundamental, Gaya geser dasar (Base shear), Partisipasi massa, Simpangan (Drift), Pembebanan grafitasi dan Perpindahan base isolator pada struktur yang direncanakan (Fixed Based \& Isolation) di kota surabaya telah memenihi persyaratan.

3. Hasil perhitungan struktur primer yang dilakukan telah memenuhi syarat terhadap kontrol kuat penampang, kontrol geser, kontrol interaksi geser lentur dan lendutan.

4. Hasil perhitungan base isolator (kekakuan horizontal, luasan \& dimensi) yang dilakukan telah memenuhi syarat terhadap kontrol perpindahan base isolator dan kontrol struktur dengan sistem isolasi.

5. Hasil perhitungan bangunan bawah telah memenuhi persyaratan dimensi dan kontrol akibat geser.

\section{B. Saran}

Saran yang dapat diberikan berdasarkan hasil analisa dalam Studi ini meliputi:

1. Diperlukan studi lebih lanjut mengenai perencanaaan struktur dengan menggunakan base isolator tipe high damping rubber bearing (HDRB) berdasarkan SNI 1726:2012 dan peraturan-peraturan lainnya agar dapat diketahui keunggulan penggunaan base 
isolator dalam meredam gaya gempa pada isolation structure dibandingkan dengan fixed based structure.

2. Diperlukan studi lebih lanjut mengenai perilaku gedung tinggi dengan Sistem Isolation Structure dengan memperhatikan aspek teknis, ekonomis dan estetika.

\section{DAFTAR PUSTAKA}

[1] Natawidjaja, D. Hilman, and A. Widodo, "Surabaya Rawan Gempa," LIPI, 2009. [Online]. Available: http://lipi.go.id/berita/single/surabaya-rawan-gempa-/3197.

[2] D. Qoernia, Penentuan Nilai Parameter Dynamic Absorber Berbasis Frekuensi. Surabaya: ITS Press, 2010.

[3] Z. Arifin, "Modifikasi Perancangan Struktur Komposit Baja dan Beton pada gedung RSUD Kepanjen-Malan," Institut Teknologi Sepuluh Nopember, 2011.

[4] A. Setiawan, Perencanaan Struktur Baja dengan Metode LRFD. (Berdasarkan SNI 03-1729-2002). Jakarta: Erlangga, 2008.

[5] M. Mursyid, "Modifikasi Perencanaan Struktur Gedung Perkantoran Telkomsel di Surabaya Barat Menggunakan BajaBeton Komposit," J. Ilm. Tek. Sipil, vol. 11, no. 1, 2013.

[6] N. Heriandes, "Perancangan Modifikasi Struktur Gedung Dinas Prasarana Jalan, Tata Ruang dan Permukiman Provinsi Sumatera Barat Menggunakan High Damping Rubber Bearing (HDRB),"
Surabaya, 2015

[7] Badan Standardisasi Nasional, "SNI 03-1729-2002: Tata Cara Perencanaan Struktur Baja Untuk Bangunan Gedung," Jakarta, 2002.

[8] Badan Standardisasi Nasional, "SNI 1729-2015: Spesifikasi untuk Bangunan Gedung Baja Struktural,” Jakarta, 2015.

[9] Direktorat Penyelidikan Masalah Bangunan, "Peraturan Pembebanan Indonesia Untuk Gedung 1983,” Bandung, 1983.

[10] Badan Standarisasi Nasional, "SNI 1727:2013 Beban Minimum Untuk Perancangan Bangunan Gedung dan Struktur Lain," Jakarta, 2013.

[11] Badan Standardisasi Nasional, "SNI 1726-2012: Tata Cara Perencanaan Ketahanan Gempa untuk Bangunan Gedung,' Jakarta, 2012.

[12] J. M. Kelly and F. Naeim, Design of Seismic Isolated Structure From Theory to Practice. New York: John Wiley \& Sons Inc, 1999.

[13] Badan Standarisasi Nasional, "Tata Cara Perencanaan Struktur Baja Untuk Bangunan Gedung (SNI 03-1729-2002)," Bandung, 2002.

[14] M. Ibrahim and Isdarmanu, Buku Ajar Struktur Baja I. Surabaya ITS Surabaya, 2006.

[15] H. Wahyudi, Daya Dukung Pondasi Dalam. Surabaya: Jurusan Teknik Sipil FTSP - ITS, 1999.

[16] Badan Standar Nasional, "Tata cara Perhitungan Struktur Beton Untuk Bangunan Gedung ( SNI 2847:2013 ),” Jakarta, 2013. 